\title{
US plans for virtual laboratories by Internet
}

THE US National Science Foundation (NSF) is to launch a project to create a high-speed computer network that will allow US scientists to carry out activities - such as collaborating in virtual reality laboratories and manipulating instruments by remote control - that are impossible to do properly on the existing Internet.

NSF also hopes that the programme, known as 'Connections to the Internet', will encourage the development of technologies that would allow its planned high-speed network to be grafted onto the existing network.

Since last year, NSF has been leasing a 155-megabit very high-speed Backbone Network Service (vBNS) from the telephone company MCI. Until now, the vBNS has linked only NSF's supercomputers (see diagram) and has had few connections to the Internet.

In future, however, NSF will ask researchers to submit proposals on ways of using the backbone for highspeed networking. It will also fund high-speed connections from their home campuses to the vBNS, according to Mark Luker, director of both the vBNS and the new programme.

The immediate impact of such The National Science Foundation's Internet 'backbone' grants will be to allow scientists at a following privatization last year. NSF now funds only the highfew dozen universities to interact at speed vBNS linking its five supercomputer centres ( $\nleftarrow$ ). The high speeds for the first time. rest of the backbone is run by commercial, regional and Researchers will be able to operate national network service providers (NSPs).

instruments such as telescopes by remote control, and collaborate using virtual reality laboratories.

But the prospect of gaining access to the vBNS is also a 'carrot' which NSF hopes will eventually encourage universities to invest their own money in upgrading local networks, and in doing so, create the embryo of a national high-speed network.

Building such a network is the only way to bring down the costs of high-speed networking. Leasing a direct high-speed link connecting one university to another can cost as much as $\$ 500,000$ a year, according to Thomas DeFanti, director of the Electronic Visualization Laboratory at the University of Illinois in Chicago. In contrast, a 155megabit link to the vBNS backbone, which in turn would connect to many other campuses, costs only $\$ 66,000$ a year.

With some clever engineering, some high-performance tasks can already be carried out through the Internet. But campus Internet links are becoming congested as students flock to use the World Wide Web (WWW), which uses up much more bandwidth than either e-mail or file transfer.

As a result, many researchers feel that high-performance computing has become almost impossible, while the transfer of large data files often takes a long time.

But according to Luker, the need for high-speed networking is due less to the problems of congestion than to the wish of researchers to develop new ways of collaborating with each other. "We have people who want to make more sophisticated use of networks, but they are stymied," he says. "They have no way to do it short of leasing their own lines."

The Internet was not designed for highspeed applications, which typically require not only high bandwidth but also close synchronization between computers. Instead, it was planned primarily to make the most effi-

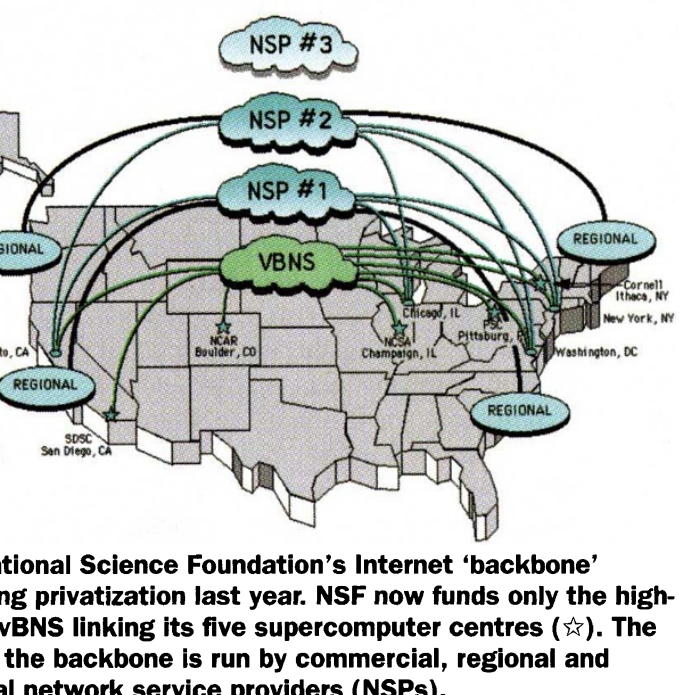
cient use of telephone lines, by smoothing out over both time and space the uneven stream of data packets from applications such as e-mail, file transfer and the WWW.

In particular, the design of Internet means that its response times are highly variable. Operating a telescope by remote control using Internet can be like driving a car whose response to the steering wheel may be ten seconds, unknown, or vary from one second to the next, says DeFanti.

Building a separate high-speed network for researchers does not solve the problem, says Luker, who claims it would defeat a general goal of sharing network resources, and be impossible to scale up economically. NSF's vision, he says, is "a single Internet that supports all services".

But neither would simply linking the two networks together be a solution, as the highspeed network would be quickly invaded by hordes of web-browsing packets. A technical 'fix' is first needed that would either give priority on the hybrid Internet to highperformance applications or code such traffic so that it is diverted to the high-speed backbones. (At present, the Internet treats all packets alike).

Stimulating the development of this technical fix is one goal of NSF's new programme. The agency will not merely provide researchers with a direct line to the vBNS, but will also ask universities to upgrade their networks to handle both traditional Internet traffic and traffic destined for the vBNS. This should be done in a way that can be scaled up economically to the dimensions of the Internet, adds Luker.

There is no shortage of ideas about how this prioritization could be achieved. One way would be to reprogramme 'routers' on the network to sort data packets according to the address of the sender, as packets from known high-speed computer users would be automatically routed to the vBNS.

NSF hopes that whatever technical solution emerges, the end result will be an improved service, which Luker points out cannot currently be bought on the Internet. According to Luker, NSF is introducing the concept of prioritization to Internet traffic, with users paying first- or third-class, depending on the service they want.

NSF's move has some familiar aspects. The agency catalysed the early growth of the Internet in the 1980s by financing a national 'backbone' to which campuses could connect.

Similarly, NSF funding for upgrading campus networks to carry highspeed prioritized traffic could eventually lead to the creation of a national high-speed network.

Nonetheless, the early growing pains of 'Internet II' are likely to be much greater than those of the current network. The circumstances are very different. The Internet originally grew out of university and other publicly supported networks; by the time providing Internet connections was transferred to commercial operators, it had become what economists refer to as a 'commodity business', and prices were quickly driven down by fierce competition.

This time the situation is reversed. The three US national high-speed 'backbone' networks are owned by telephone companies - MCI, Sprint and AT\&T - while the extensive cabling in urban areas is also owned by private companies.

The current high costs of high-speed networking mean that services such as online video are not yet economic. With few profits to be made from an embryonic network, the commercial companies involved are reluctant to connect with each other, preferring to hold out and fight for market dominance. Costs will eventually collapse, predicts DeFanti, "but not for several years".

Indeed, while Internet I was born in America, 'Internet II' may originate in Europe, where many countries are nearing completion of national high-speed research networks. Such state-owned networks may be easier to link up, says DeFanti, adding that "there is less of the need for a business case at every turn".

Declan Butler 